\section{Psicologia Escolar \\ e Educacional}

ARTIGO

DOI: http://dx.doi.org/10.1590/2175-35392020217251

Elocid - e217251

\title{
FRACASSO ESCOLAR E CONSELHO TUTELAR: UM ESTUDO SOBRE OS CAMINHOS DA QUEIXA ESCOLAR
}

\author{
Gabriela de Conto Bett ${ }^{1} \mathbb{D} ;$ Maria Júlia Lemes ${ }^{1 \mathbb{C}}$
}

\section{RESUMO}

Este artigo decorre de pesquisa realizada sobre os caminhos percorridos pela queixa escolar no Sistema de Garantia de Direitos de Crianças Adolescentes - SGD. O objetivo foi investigar as queixas levadas ao Conselho Tutelar e seus respectivos encaminhamentos. A pesquisa foi realizada no ano de $2017 \mathrm{em}$ quatro Conselhos Tutelares de uma das comarcas da região Oeste do Paraná, e tem como referencial teórico-metodológico a Psicologia Escolar e Educacional de base histórico-crítica. Seu delineamento foi de cunho quantitativo e qualitativo, com a adoção de análise documental e entrevistas realizadas com conselheiros tutelares. Observarmos que a maior demanda dos conselhos tutelares provém da educação, havendo um número significativo de queixas escolares, as quais são encaminhadas a outros setores como Assistência Social, Saúde, Ministério Público e Poder Judiciário. Os motivos dos encaminhamentos nos permitiram aprofundar a compreensão acerca das respostas dadas à queixa escolar e esboçar alternativas para o enfrentamento do fracasso escolar.

Palavras-chave: Psicologia Educacional; fracasso escolar; defesa da criança e do adolescente.

\section{School Failure and Guardianship Council: A Study on the Paths of School Complaint}

\begin{abstract}
This article is the result of research conducted on the paths taken by the school complaint in the Adolescent Children Rights Guarantee System - SGD. The objective was to investigate the complaints brought to the Guardianship Council and their referrals. The research was conducted in 2017 in four Guardianship Councils of one of the regions of Western Paraná, and has as theoretical-methodological framework the School and Educational Psychology of historical-critical basis. Its design was quantitative and qualitative, with the adoption of document analysis and interviews with tutelary counselors. It should be noted that the highest demand from the tutelary councils comes from education, with a significant number of school complaints, which are referred to other sectors such as Social Assistance, Health, Public Prosecution and Judiciary. The reasons for the referrals allowed us to deepen our understanding of the answers given to the school complaint and to outline alternatives for coping with school failure.
\end{abstract}

Keywords: Educational Psychology; school failure; child and adolescent defense.

\section{Fracaso escolar y consejo tutelar: un estudio sobre los caminos de la queja escolar}

\section{RESUMEN}

Este artículo proviene de una investigación realizada sobre los caminos recorridos por la queja escolar en el Sistema de Garantía de Derechos de Niños Adolescentes - SGD. El objetivo fue investigar las quejas llevadas al Consejo Tutelar y sus respectivos encaminamientos. La investigación fue realizada en el año 2017 en cuatro Consejos Tutelares de una de las comarcas de la región Oeste de Paraná, y tiene como referencial teórico-metodológico la Psicología Escolar y Educacional de base histórico-crítica. Su delineamiento fue de cuño cuantitativo y cualitativo, con la adopción de análisis documental y entrevistas realizadas con consejeros tutelares. Se percibió que la mayor demanda de los consejos tutelares proviene de la educación, habiendo un número significativo de quejas escolares, las cuales son encaminadas a otros sectores como Asistencia Social, Salud, Ministerio Público y Poder Judiciario. Los motivos de los encaminamientos permitieron a nosotros profundizar la comprensión acerca de las respuestas dadas a la queja escolar y dibujar alternativas para el enfrentamiento del fracaso escolar.

Palabras clave: Psicología Escolar e Educacional; fracaso escolar; defensa de niños y adolescentes.

1 Universidade Estadual de Maringá - Maringá - PR - Brasil; gabicbett@gmail.com; mjulialemes@gmail.com 


\section{INTRODUÇÃO}

A pesquisa que aqui apresentamos emerge do cotidiano de trabalho no Serviço Auxiliar da Infância e Juventude do Tribunal de Justiça do Estado do Paraná - TJ/PR, onde, em contato com a rede de serviços do Sistema de Garantia de Direitos de Crianças e Adolescentes - SGD, observamos uma íntima relação entre escola, Conselho Tutelar - CT - e justiça da infância e juventude.

Os Conselhos Tutelares nascem com o Estatuto da Criança e do Adolescente - ECA (Lei Federal no 8.069/90, 1990), no intuito de desjudicializar o cotidiano de crianças e adolescentes, haja vista o histórico da legislação e da assistência à infância no país que é marcado pela criminalização da infância pobre nos tribunais. Sua atribuição principal é fiscalizar os direitos fundamentais de crianças e adolescentes, dentre os quais encontra-se a educação.

Nesse contexto, apesar de poucos trabalhos versarem sobre o assunto, há alguns anos já tem sido observada a presença da queixa escolar no cotidiano dos conselhos tutelares, como mostraram Souza, Teixeira e Silva (2003). Os encaminhamentos dados à queixa pelos conselhos, porém, ainda são pouco explorados, motivo pelo qual entendemos como necessário investigar o fluxo da queixa escolar a partir do CT. Isto porque as relações que se estabelecem entre a educação e o direito da criança e do adolescente podem contribuir para a manutenção das desigualdades no interior da educação e da justiça, que são entendidas aqui como produto social, imbuídas de contradições e emissoras de uma posição política que reflete as aspirações e interesses de uma classe.

\section{DIREITO À EDUCAÇÃO E DIREITO DA CRIANÇA E DO ADOLESCENTE: O ENTRELACE DAS LEGISLAÇÕES}

A constituição da educação como Direito Social e como um Direito da Criança e do Adolescente, nos direciona a reflexões acerca da articulação entre legislações específicas, quais sejam: a Constituição Federal de 1988, o Estatuto da Criança e do Adolescente e a Lei de Diretrizes e Bases da Educação. A história do referido direito é marcada pela divisão de classes típica da sociedade capitalista, desde o período colonial, ganhando maior vigor a partir de 1920 quando se inicia, propriamente, o capitalismo no Brasil (Nagle, 1976; Romanelli, 1986).

Como discutido por Saviani e Duarte (2012), a educação, que se destina à formação do homem, no sentido da apropriação do legado cultural produzido na história da humanidade, e que tem a escola como instituição imprescindível na tarefa de mediação cultural para a formação humana, tem sido acessada de modo desigual pelas diferentes classes. Assim, o desenvolvimento da totalidade dos seres humanos não é possibilitado a todos, já que a escola assume papel central na trans- formação do homem, na medida em que se constitui como espaço por excelência da socialização dos conhecimentos científicos, fundamentais para a passagem do conhecimento empírico ao abstrato, estabelecendo mediações entre o conhecimento e o indivíduo, e o consequente desenvolvimento do gênero humano (Saviani \& Duarte, 2012).

Na sociedade capitalista sob a égide do ideário liberal, as contradições expressas no posicionamento do Estado se impõem à realização de uma educação que propicie o referido desenvolvimento, em especial à classe pobre trabalhadora, cujas dificuldades de acesso e permanência na escola são ainda um desafio a ser superado. Tais contradições são evidentes na história da educação brasileira, que desde o período colonial foi direcionada diferentemente para cada classe: aos pobres uma educação utilitarista e à classe dominante uma educação em seu mais alto nível de graduação (acesso à universidade e aos conhecimentos das humanidades, artes e filosofia, entre outros) (Romanelli, 1986; Nagle, 1974). Trata-se de uma instituição que nasce das necessidades de reprodução da sociedade de classes, o que marca sua contradição fundamental expressa no limite e na possibilidade de propiciar a apropriação do legado cultural e o desenvolvimento da consciência. (Lessa, 2012; Duarte, 2012).

Em nosso país, a ideia do ensino como direito de todos e dever do Estado teve como mola propulsora a necessidade de formação para o trabalho, sendo, portanto, defendido por alguns juristas, desde a década de 1930, como obrigatório (Romanelli, 1986). Por muito tempo, a obrigatoriedade fora uma imposição ao indivíduo sem que se refletisse sobre suas condições de acesso à educação. $O$ referido acesso exigia a presença do Estado, mas é só com o fim da ditadura militar em 1985 e a abertura política que os movimentos sociais ganham forças em direção à garantia de direitos. $O$ Estado se manteve distante da proteção dos direitos sociais até que assume tais responsabilidades na Constituição Federal de 1988, a qual, em seu artigo 208, define que é dever do Estado a garantia de ensino fundamental obrigatório e gratuito, inclusive para aqueles que não o tiveram em idade própria, além de estender esse direito ao ensino médio (Brasil, 1988). A gratuidade do ensino público passa a abranger qualquer dos seus níveis e, diferentemente de outros direitos sociais, a educação está vinculada à obrigatoriedade escolar consistindo em direito público e subjetivo, o qual passa a ser garantido por outros dispositivos como a Lei de Diretrizes e Bases da Educação Nacional - LDB e o Estatuto da Criança e do Adolescente - ECA (Lei Federal no 8.069/90, 1990).

Associando-se a LDB com o ECA, observamos que: 0 ensino fundamental, com duração mínima de oito anos, se torna obrigatório e gratuito, inclusive para os que não tiveram acesso em idade própria; estende-se a obriga- 
toriedade ao ensino médio; garante-se atendimento educacional especializado aos portadores de deficiência; assegura-se $o$ atendimento em creches e escolas a crianças de 0 a 6 anos; assegura-se o acesso aos níveis mais elevados do ensino. Tudo isso como um dever do Estado (art. 54 do ECA) (Lei Federal no 8.069/90, 1990).

Um dos pilares do ECA é seu art. $4^{\circ}$, que encerra o "princípio da prioridade absoluta" à criança e ao adolescente, os quais passam a ser sujeitos de direitos conforme estabelece a Doutrina da Proteção Integral, em face à antiga Doutrina da Situação Irregular, a qual deixava claro que crianças e adolescentes eram objeto de intervenção estatal apenas quando se observasse que estavam em situação irregular de mendicância, vadiagem, abandono e delinquência (Sêda, 1996).

Ressaltamos agora que, sendo a educação básica um direito público subjetivo, um direito da criança e do adolescente, e tendo a característica de obrigatoriedade e gratuidade, foi necessário criar ferramentas para sua garantia. $O$ combate à evasão escolar se torna premente e o ECA cria uma ferramenta para fiscalizar a violação dos direitos fundamentais da criança e do adolescente: o Conselho Tutelar.

Em seu art. 101, o ECA define as medidas protetivas a serem aplicadas, quando da observância de ameaça ou violação de direitos, quais sejam: I. encaminhamento aos pais ou responsável, mediante termo de responsabilidade; II. orientação, apoio e acompanhamento temporários; III. matrícula e frequência obrigatórias em estabelecimento oficial de ensino fundamental; IV. inclusão em programa comunitário ou oficial de auxílio à família, à criança e ao adolescente; V. requisição de tratamento médico, psicológico ou psiquiátrico, em regime hospitalar ou ambulatorial; VI. inclusão em programa oficial ou comunitário de auxílio, orientação e tratamento a alcoólatras e toxicômanos; VII. acolhimento institucional; VIII. inclusão em programa de acolhimento familiar; IX. colocação em família substituta - art. 101 do ECA (Lei Federal no 8.069/90, 1990).

Dentre as atribuições do CT (art. 136 do ECA, Lei Federal $n=8.069 / 90,1990)$, encontram-se: atender a crianças e adolescentes, aplicando as medidas protetivas; atender e aconselhar os pais ou responsáveis; requisitar serviços públicos nas áreas de saúde, educação, serviço social, previdência, trabalho e segurança; representar junto à autoridade judiciária, nos casos de descumprimento injustificado de suas deliberações; encaminhar ao Ministério Público notícia de fato que constitua infração administrativa ou penal contra os direitos da criança ou adolescente; representar ao Ministério Público, para efeito das ações de perda ou suspensão do poder familiar, após esgotadas as possibilidades de manutenção da criança ou do adolescente junto à família natural. Das medidas aplicáveis pelo CT aos pais ou responsáveis (art. 129 do ECA), encontram-se, entre outras, a obrigação de matricular o filho ou pupilo, acompanhar sua frequência e aproveitamento escolar; obrigação de encaminhar a criança ou adolescente a tratamento especializado. O CT também deve ser acionado pelos dirigentes de estabelecimentos de ensino fundamental quando houver: casos de maus-tratos envolvendo seus alunos; reiteração de faltas injustificadas e de evasão escolar, esgotados os recursos escolares; elevados níveis de repetência - art. 55 do ECA (Lei Federal no 8.069/90, 1990). Chamamos a atenção para o fato de que o acionamento do CT deve se dar apenas quando esgotados os recursos escolares.

Exposta a letra da lei, abordaremos na sequência alguns aspectos acerca da produção do fracasso escolar, haja vista as evidências de que a queixa escolar (expressão do referido fracasso) tem sido a principal demanda do Conselho Tutelar, conforme dados da pesquisa que aqui apresentamos.

\section{A PRODUÇÃO DO FRACASSO ESCOLAR E A QUEIXA ESCOLAR}

Existem problemáticas frequentes na sociedade brasileira desde os primeiros movimentos em direção à escolarização da população, quais sejam: ingresso, permanência do aluno na escola e repetência. A evasão escolar, as políticas educacionais e outros aspectos relacionados à aprendizagem vêm denunciando a lógica excludente da educação no sistema capitalista. Os índices de reprovação ou abandono em 2016, segundo indicadores do INEP são, respectivamente, de 5,9\% e $0,9 \%$ nos anos iniciais; $11,4 \%$ e $3,1 \%$ nos anos finais e $12,0 \%$ e $6,6 \%$ no ensino médio.

Devemos atentar, pois, para as respostas sócio-políticas dadas à questão do fracasso escolar no decorrer da história da educação no país. Não há uma linha cronológica fixa acerca das teorias sobre o fracasso escolar, mas é evidente a predominância de concepções preconceituosas, calcadas em fundamentos pragmáticos de acordo com o modo capitalista de produção de ideias, cuja expressão maior é o liberalismo. A exemplo disso, teorias racistas impulsionadas pela eugenia, marcadamente presente na psicologia diferencial, reforçaram a ideia de que as aptidões humanas seriam herdadas e o fracasso escolar seria fruto de anormalidades orgânicas das crianças (Patto, 1993).

Embasadas nas teorias evolucionistas de Darwin, as diferenças e desigualdades eram explicadas como fruto de distinções anatômicas e fisiológicas hereditárias entre as raças. Na década de 1930, a perspectiva eugenista de Galton adentrou a Psicologia e a Pedagogia incidindo diretamente no contexto educacional brasileiro, a partir do que emergiu a ampla utilização de testes mentais para medir as aptidões dos escolares, devido ao aumento da demanda por escolas, à necessidade de explicar as diferenças de rendimento da clientela escolar e de justificar o acesso desigual aos níveis escolares 
(Wanderbrook Junior, 2009).

Posteriormente, as explicações que, até então, se centravam nas características individuais dos alunos deslocaram-se para a família e para o ambiente (Paula \& Tfouni, 2009). Não se tratava mais de uma explicação biológica, apenas, mas também de aspectos entendidos como culturais, os quais motivaram pesquisas sobre as relações familiares e as práticas de criação infantil a partir do princípio da prevenção de doenças levado ao campo da saúde mental e da educação pelos médicos higienistas, os quais acreditavam que a infância seria o melhor momento para coibir possíveis desvios que acarretariam problemas futuros na sociedade (Figueira \& Boarini, 2014). Liberalismo, Medicina, Psicologia e Pedagogia, unem-se na tarefa de encontrar as causas do fracasso escolar nas anormalidades orgânicas e/ou na família daqueles que não aprendem por inaptidões entendidas como naturais As teorias alicerçaram-se nas perspectivas liberal e inatista, a partir das quais a educação brasileira foi pensada e planejada nas primeiras décadas do século $X X$.

Da mesma forma, tais teorias sustentaram as ações de juristas que, a partir de princípios moralistas, em nome de uma suposta proteção de crianças e adolescentes, lançaram mão de uma "linha preventiva" que justificava a retirada de crianças de suas famílias "perigosas" e a institucionalização em nome da defesa social (Rizzini \& Pilotti, 2009). A legislação e a assistência à infância no Brasil são marcadas pelo controle da infância pobre marginalizada, com base nas perspectivas individualizantes que contribuíram para a institucionalização de crianças e a culpabilização única e exclusiva da família pelos problemas sociais (Patto, 1993; Rizzini \& Pilotti, 2009).

É apenas na década de 1980 que começa a ser denunciado o caráter classista da educação onde a discriminação e a justificação das desigualdades aparecem como a razão de ser do sistema escolar (Angelucci, Kalmus, Paparelli, \& Patto, 2004). Também na década de 1980 é promulgado o ECA, como uma forma de superação das legislações anteriores.

Com a perspectiva de investigar o percurso da queixa escolar, que vem alocando crianças nas estatísticas de fracasso escolar, passamos a descrever nosso estudo.

\section{MÉTODO}

A pesquisa foi realizada em quatro Conselhos Tutelares pertencentes a uma das comarcas da região oeste do Paraná no ano de 2017. A teoria de que nos servimos como ponto de partida para a compreensão e explicação do objeto é de orientação marxista, a qual demonstra que as relações sociais estão intimamente ligadas às forças produtivas.

Considerando que a expressão do real se manifesta e se constitui por elementos objetivos e subjetivos, quantitativos e qualitativos, intrinsecamente relacionados, e que a lógica dialética própria à epistemologia marxiana supera a lógica formal (Martins, 2006), o delineamento da pesquisa se deu em ambas as direções. No âmbito qualitativo, além da descrição da queixa escolar, procuramos compreender o processo dos encaminhamentos das queixas que passam pelo $\mathrm{CT}$, com vistas ao modo como expectativas se traduzem em atividades. No sentido quantitativo, realizamos o levantamento numérico das queixas que chegavam ao CT bem como dos encaminhamentos realizados por esse órgão aos diferentes setores, dando visibilidade ao movimento objetivo de direcionamento da queixa escolar a partir do conselho tutelar.

A primeira fase envolveu a pesquisa documental com o levantamento estatístico acerca dos encaminhamentos realizados pelas escolas aos referidos conselhos no ano de 2016. Foram disponibilizados e consultados 250 ofícios, dentre os quais 180 eram provenientes de escolas. Além disso, considerando que ofícios não constituem o único meio através do qual se comunicam os órgãos públicos (telefonemas também são usados para que um serviço público comunique o outro sobre uma dada situação ocorrida entre crianças e adolescentes e realize encaminhamentos), foram consultadas 67 pastas de usuários (uma forma de arquivamento físico onde, pelo nome da criança/adolescente, encontram-se anotações sobre ela), e um livro do qual se utilizava um dos conselhos para registrar ocorrências diárias, dentre as quais encontravam-se ligações provenientes das escolas com queixas escolares. Em um segundo momento, os conselheiros foram consultados sobre os encaminhamentos que deram a cada caso, e os documentos de seus encaminhamentos (98 ofícios) também foram analisados.

Por fim, foram realizadas entrevistas individuais semi-estruturadas com quatro representantes dos conselhos tutelares, com vistas à clarificação dos dados encontrados nos documentos e apreensão dos porquês dos encaminhamentos. O roteiro utilizado para a entrevista foi organizado em dois eixos. O primeiro buscou realizar um levantamento do perfil dos conselheiros, contendo informações como sexo, idade, formação, experiência profissional e tempo de trabalho no CT. O segundo buscou obter informações relacionadas à prática profissional e ao recebimento e encaminhamento das queixas escolares. Foram tratados temas como: o cotidiano do CT e sua relação com a educação (o que as escolas têm trazido como queixas e de que maneira o fazem; quais as medidas protetivas aplicadas pelo conselho tutelar nos casos relacionados à educação); se há encaminhamentos a serviços de saúde, assistência social, Ministério Público e o porquê de tais encaminhamentos; a percepção dos conselheiros acerca de suas 
atribuições e das queixas escolares.

A análise dos dados se deu à luz da concepção marxista cujo princípio fundamental é o de que a realidade encerra a materialidade histórica dos processos de produção e reprodução da existência dos homens. A expressão singular dos caminhos seguidos pela queixa escolar e das concepções que os norteiam revelam a imediaticidade de um fenômeno, o qual deve ser lido em sua complexidade a partir da totalidade histórico-social.

\section{RESULTADOS E DISCUSSÃO}

Os conselhos tutelares recebem diversas notificações sobre as mais variadas situações cotidianas de crianças e adolescentes, dentre as quais, a demanda escolar assume maior representatividade. Do total de 288 queixas escolares que chegaram aos conselhos, as mais representativas consistiram em: faltas $(55,9 \%)$, notificação de alunos enfermos (7,29\%), "gazear" aula $(5,90 \%)$ e queixas sobre comportamentos de alunos $(5,55 \%)$. Os outros $25,36 \%$ representam diversas queixas tais como: baixo rendimento escolar, crianças cujos responsáveis não as haviam buscado na escola ao final da aula, suspeita de violência física intrafamiliar e abuso sexual, violência intraescolar (bullying, preconceito racial); pedido de encaminhamento a serviços especializados (psicologia, fonoaudiologia); violência praticada por professor contra aluno e suspeita de uso de drogas.

Ressaltamos que, ainda que a categoria "aluno enfermo" tenha sido expressiva, isso se deve a dois conselhos apenas e aponta particularidades da relação do conselho com a comunidade escolar naqueles municípios. Nesses casos, o acionamento do CT foi feito por creches que acionam os conselheiros para buscarem a criança enferma e levá-la para casa ou a uma unidade básica de saúde. Já a evasão escolar, baixa frequência e faltas escolares são comuns a todos os conselhos. 0 acionamento do CT por faltas se deve à obrigatoriedade de notificação - art. 56 do ECA, que chama à responsabilidade o poder público e os pais e responsáveis para que haja oferta de vagas em escolas e cumprimento da obrigatoriedade de matricular os filhos e assegurar sua frequência (Lei Federal no 8.069/90, 1990). Nestes casos, compreendemos a queixa escolar no sentido da proteção de crianças/adolescentes que devem ter garantido o direito à educação. Por outro lado, a forma como as queixas se apresentam sugere outras reflexões. Observamos que as queixas de faltas/infrequência são feitas sem que antes se esgotem os recursos escolares, como previsto na LDB e no ECA, sugerindo que, além do distanciamento entre escola e família, a visão preconceituosa predominante em nossa história acerca do aluno e da família pobre, "merecedores" de práticas opressivas - no caso, pelas vias do Conselho Tutelar ainda se faz presente, apesar das teorias críticas surgidas na década de 1980 sobre as dificuldades no processo de escolarização. Devemos pontuar que a parcela da população atendida pelos conselhos tutelares é, em grande parte, aquela proveniente da classe pobre, denunciando não uma maior procura dessa parcela da população pela garantia de seus direitos, mas sim, o quanto a população pobre tem sido aviltada do acesso à educação e responsabilizada pelo fracasso escolar.

Quando analisamos a evasão escolar, as faltas reiteradas, ou mesmo os níveis de repetência, atentamos para o que Patto (1993) anunciou como produção do fracasso escolar. De acordo com a autora, na história da educação brasileira há uma visão depreciativa das classes populares que atribui a evasão escolar ao desinteresse dos pais. A autora demonstrou que tanto a evasão como a repetência recebiam explicações embebidas de preconceitos que atribuíam exclusivamente à classe pobre a responsabilidade sobre o insucesso escolar, mantendo, assim, a coesão da estrutura social burguesa (Patto, 1993).

Ao que tudo indica, as mesmas concepções continuam pautando as explicações sobre o fracasso escolar, e nesse contexto temos uma legislação que legitima a responsabilização dos pais e responsáveis. Mas não estaríamos assim, transformando a superação dos problemas sociais em questões individuais? Como responsabilizar a família pobre, cujo acesso à educação se dá de maneira desigual em nossa sociedade, pelo (in) sucesso escolar?

De acordo com Silva e Leonardo (2012), devemos compreender o contexto no qual está inserida a produção do sucesso e/ou fracasso escolar, a gênese social desses, uma vez que a escola funciona sob o aporte de uma sociedade excludente, desigual e classista. Como fundamentam as autoras, o sucesso e/ou fracasso escolar, deve ser considerado a partir da gênese social dos problemas educacionais, o que envolve "um amplo contexto social e político característico de uma sociedade desigual e dividida em classes" (Silva \& Leonardo, 2012, p.74).

Além da faltas e evasão, comuns a todos os conseIhos, queixas sobre comportamentos também foram encontradas nos quatro conselhos. De formas diversas, todos os entrevistados relataram que as escolas se queixam do que aqui colocamos sob a categoria "comportamentos inadequados", tais como: indisciplina, agressividade, não realizar tarefas em sala, brigas, desrespeito ao professor, inquietude, "transtornos na sala de aula", vandalismo, desinteresse dos alunos, ausência em sala de aula (gazear), até a falta de uso de uniformes, ou mesmo "cheiro desagradável" e "uso de roupas apertadas" por parte das meninas.

Esses dados refletem o que vêm apontando algumas pesquisas acerca da queixa escolar e da patologização e medicalização da infância e dos processos educativos 
(Leonardo, Leal, \& Rossato, 2012; Facci, Meira, \& Tuleski, 2012), as quais explicam que os obstáculos advindos das dificuldades de apropriação dos conteúdos escolares são lidos a partir de paradigmas tradicionais centrados no indivíduo que atribuem à incapacidade do aluno as respostas para o fracasso escolar. Assim, os supostos problemas emocionais e transtornos de comportamento se tornam a principal justificativa do fracasso escolar, escamoteando seus reais determinantes, tais como a falta de investimento estatal, a adoção de perspectivas liberais no campo teórico-metodológico, entre outros aspectos decorrentes do liberalismo econômico que incidem diretamente na formulação das Políticas Educacionais e se materializam no cotidiano como dificuldades.

Da mesma forma, tais concepções orientam as ações dos conselheiros, como veremos agora. Os dados colhidos nos mostram que a primeira ação é a busca pelos familiares. No momento do encontro com as famílias, os pais são orientados sobre as previsões legais do ECA, em especial, sobre sua responsabilidade quanto à garantia do direito à educação. Ao mesmo tempo, os conselheiros "aconselham", conforme suas atribuições, sobre a importância da educação, sobre formas de modificar o cotidiano para melhor atender às exigências legais, e sobre como educar os filhos (aconselhamentos quanto a limites e maneiras de se comportar com os filhos, de acordo com as concepções de cada conselheiro). Outra ação comum é o encaminhamento a outros setores, na expectativa de que a omissão e negligência familiar sejam solucionadas.

Encontramos 95 encaminhamentos da queixa escolar à rede intersetorial, totalizando $32,9 \%$ de direcionamentos das queixas a outros setores. Notamos que os encaminhamentos mais expressivos que os conselhos têm realizado são, em primeiro lugar, à assistência social $(31,57 \%)$, em segundo à saúde $(28,42 \%)$, em terceiro ao Ministério Público (22,10\%), seguidos da Polícia Civil $(4,21 \%)$, e do Poder Judiciário $(2,10 \%)$.

O maior número de encaminhamentos é feito a serviços de assistência social e saúde, devido à presença do psicólogo, sendo o atendimento psicológico a maior requisição de serviços públicos feitas pelo CT. Nas entrevistas, a ênfase no papel do psicólogo é marcante, pois os conselheiros apresentaram a crença de que o atendimento psicológico seria capaz de solucionar a queixa escolar na medida em que atuaria sobre os problemas emocionais do aluno e dos conflitos familiares. Em outros momentos o psicólogo foi apontado como aquele que teria a habilidade para "convencer" os familiares sobre a importância da escola, como na fala de um conselheiro: se... ele reluta em não mandar, aplicamo uma medida de proteção... Se ele não cumprir, é lógico que a gente encaminha... pra psicóloga e assistente social tentar convencer da importância da educação escolar.
A demanda para o atendimento psicológico parece evidenciar a ideia de um serviço redentor dos problemas sociais e entendemos que isso tem como base a função histórica que assume a Psicologia a partir de seu movimento de psicologização e individualização dos fenômenos sociais. As teorias tradicionalmente utilizadas no campo da Educação e da Psicologia, com base na ciência moderna, convergiram com as perspectivas liberal e inatistas, centradas no indivíduo, desconsiderando a relação dialética indivíduo-sociedade/ subjetividade-objetividade (Patto, 1993; Angelucci et al., 2004; Boarini, 2012).

Ao Centro de Referência de Assistência Social CRAS - são encaminhadas crianças/adolescentes cujas faltas escolares estariam associadas a supostos conflitos familiares, escassez de recursos financeiros e violência intrafamiliar. Ao setor saúde, além do prioritário atendimento psicológico, também foram solicitados atendimentos especializados nas áreas de fonoaudiologia (01) e neurologia (01). A "rebeldia" e o desinteresse em estudar, foram motivos de encaminhamento de uma adolescente de 16 anos ao Centro de Atenção Psicossocial - CAPS. Outro adolescente originou encaminhamentos ao CRAS, Unidade Básica de Saúde e Ministério Público, pois, além das faltas escolares que eram notificadas ao $\mathrm{CT}$ com frequência, havia a suspeita de uso de drogas.

Nesse cenário é necessário discutir as propostas e objetivos de cada serviço e as atribuições de seus profissionais. Sem desconsiderar a integralidade dos sujeitos e tendo ciência de que aspectos de saúde e de vulnerabilidade social podem se apresentar na escola, interferindo no processo ensino-aprendizagem, chamamos a atenção para o fato de que a crença na Psicologia como solução da queixa escolar está ancorada, justamente, nas perspectivas individualizantes que reduzem a aspectos biológicos, emocionais e/ou familiares, as diversas situações do cotidiano escolar.

Ademais, as práticas de psicólogos que recebem a demanda escolar vêm sendo alvo de discussão, pois têm se reduzido ao psicodiagnóstico, testagem psicológica, psicoterapia, além do encaminhamento a médicos para tratamento farmacológico, como demonstram os estudos de Souza (1997), Boarini e Borges (2009), Reis e Ribeiro (2012), Facci, Silva e Ribeiro (2012). Trata-se do processo de medicalização do fracasso escolar discutido por Collares e Moysés (2015) e por Facci et al. (2012), e que recai sobre a família como cobrança das escolas. O grande problema é que, "... quando se medicaliza a criança que não aprende se está acobertando uma análise da totalidade, ficando as explicações esvaziadas de uma análise dialética..." (Facci et al., 2012, p.171).

Novamente, sem negligenciar a ideia de que a pobreza e demais expressões da questão social têm seus 
impactos na aprendizagem, o que queremos aqui é chamar a atenção para a individualização de um fenômeno que está ancorado histórica e socialmente nas desigualdades sociais, na divisão da sociedade em classes e nas contradições decorrentes do capitalismo, de modo que as ações se tornam esvaziadas e sem possibilidades de transformação da realidade caótica que se apresenta.

Os encaminhamentos ao Ministério Público se deram, em sua grande maioria, devido à reincidência de faltas escolares. No total, houve 21 encaminhamentos ao MP após queixa escolar. Dentre eles, três foram realizados por suspeita de violência intrafamiliar contra a criança/adolescente; um devido a um conflito entre o diretor da escola e um aluno (neste caso o diretor xingou o aluno). Os 17 restantes se deram por faltas reiteradas.

A evasão escolar é uma violação de direitos, o que justifica a aplicação das medidas protetivas ou aquelas aplicáveis aos pais ou responsáveis. O que nos chama a atenção, porém, é que tais medidas estão centradas na criança e na família, evidenciando que a própria legislação reverbera a concepção de que não há que se questionar qualquer outra instituição. Ademais, isso não é alvo de reflexão na vida cotidiana pelos conselheiros, pois essas ideias estão assentadas na ciência idealista-positivista e na legislação. Os conselheiros exercem, exatamente, aquilo que lhe é respaldado pela lei.

Porém, concordando com Lessa (2012), a vida cotidiana é marcada pelas alienações e o fato de o Direito ser fundado pelo trabalho alienado nos mostra que devemos conceber o Direito como uma forma de justificar cotidianamente a prática e a teoria dos indivíduos, a qual tem sua origem em uma determinação social e material do pensamento, que é, em essência, alienada pela exploração do homem pelo homem. Assim, tanto o direito à educação como o direito da criança e do adolescente devem ser lidos em suas contradições.

Como discutido por Leonardo et al. (2012), essa afirmativa pode ser mais bem compreendida ao se verificar, no Brasil, apesar do ECA, um número elevado (539.702) de crianças e adolescentes de 6 a 14 anos fora da escola, bem como a taxa de menos de $70 \%$ dos jovens de 16 anos que concluem o Ensino Fundamental. Estima-se que apenas $56,1 \%$ das crianças das escolas públicas que concluíram o 30 ano do Ensino Fundamental obtêm os conhecimentos esperados para essa etapa, de acordo com o índice de leitura da Avaliação Brasileira do Ciclo de Alfabetização - Prova ABC (Leonardo et al., 2012). Esses e outros dados, segundo as autoras, evidenciam que as práticas e políticas educacionais não conseguem atingir todas as crianças em idade escolar, seja quanto à permanência na escola ou quanto ao sucesso escolar, revelando que muitas crianças estão sujeitas a um processo histórico de marginalização que tem como consequência as queixas escolares (Leonardo et al., 2012).

Somados os encaminhamentos ao MP, Poder Ju- diciário e polícia temos $21 \%$ do total dos 95 encaminhamentos, que competem com as outras duas fatias que são saúde e assistência social. À polícia e Poder Judiciário os encaminhamentos tinham como fundamento o "abandono intelectual", considerado crime na legislação brasileira.

Ainda que os encaminhamentos ao Poder Judiciário não tenham sido expressivos, há que se pensar sobre a judicialização da educação, na medida em que se fazem encaminhamentos também ao Ministério Público, com vistas a providências legais. Os conselheiros relataram que não fazem encaminhamentos diretamente ao Poder Judiciário devido ao protocolo estipulado na comarca que define que se dirijam ao Ministério Público, inicialmente.

Há, pois, a busca de mecanismos legais para dar conta da queixa escolar que se apresentou insolúvel em outros setores. Como vimos nas entrevistas, os encaminhamentos ao Ministério Público são acompanhados de falas como: "quando não tem jeito", "não tem outro remédio", ou "quando não resolve". Assim como há a crença nos psicólogos, as entrevistas indicam a crença dos conselheiros em uma "lei" que possa obrigar crianças e adolescentes a frequentarem a escola.

Nesse sentido, uma importante reflexão de Lessa (2012), acerca do "fetichismo da educação" nos é propícia, qual seja, a de que sem compreender o fundamento da crise contemporânea, preocupamo-nos em manter as crianças na escola, independentemente do aprendizado. Considerando que a escola não tem sido questionada e que a solução para a queixa escolar está na Psicologia e na Justiça, arriscamos dizer que a obrigatoriedade escolar evidencia muito mais a crise da sociedade de classes do que a preocupação com a aprendizagem.

As respostas dos conselheiros também expressam as contradições da sociedade, mesclando o reconhecimento da pobreza com sua culpabilização: ao mesmo tempo em que têm ciência da pobreza, realizam os encaminhamentos ao Ministério Público para as providências quanto aos pais omissos e negligentes, devido à persistência de faltas de alunos das famílias pobres. Longe de intentar desmerecer os conselheiros e seu trabalho, observamos que a leitura feita por eles é expressão da ideologia dominante, da estrutura social e condizente com o amparo legal da legislação da infância a qual, a despeito de todo o avanço com relação às legislações anteriores, parece ainda conter os traços higienistas que mobilizaram a sociedade na direção do ECA. Importante ressaltar que, como afirma Boarini (2012), ainda que possa ter encontrado algumas resistências no Brasil, os ideários eugenista e higienista, "continuam subsidiando o aparato jurídico e os encaminhamentos institucionais da sociedade, bem como explicando o fenômeno da subjetividade até os nossos dias" (Boarini, 2012, p. 15). 
Devemos considerar, ainda, que a formação dos conselheiros é deficitária no sentido da aquisição de conhecimentos que possibilitem o reconhecimento das contradições da legislação. Como discutido por Bazílio e Kramer (2011), são comuns aos Conselhos Tutelares a escassez e irregularidade na distribuição de fundos, a falta de recursos para a realização de simples ações e o fenômeno da desprofissionalização desse campo (multiplicação de contratos precários ou temporários; baixo ou nenhum investimento em capacitações de qualidade; rotatividade excessiva).

A questão é que nesse emaranhado, crianças e adolescentes continuam fora das escolas, como apontaram os números acerca das faltas/infrequência, assim como são as crianças/adolescentes provenientes de famílias pobres que chegam aos conselhos tutelares (Bazílio \& Kramer, 2011), de modo que podemos afirmar que a escola continua como instituição seletiva e excludente. Lembramos que as faltas constantes acarretam reprovação e que essa, por sua vez, não se revela como um mundo de possibilidades para um novo aproveitamento do que foi perdido, mas sim, um novo obstáculo.

\section{CONSIDERAÇÕES FINAIS}

Constatamos que dentre as demandas do trabalho dos conselheiros, a maior parte provém das escolas. São queixas escolares diversas relacionadas à evasão escolar/faltas/infrequência e a questões comportamentais que vão desde indisciplina, não realização de tarefas em sala, agressividade, desrespeito ao professor, até o "cheiro desagradável" e roupas sujas usadas pelos alunos. $O$ baixo rendimento escolar também se apresentou aos conselhos tutelares.

Evidenciamos o empenho dos conselheiros tutelares em garantir o direito à educação. Exemplo disso é, justamente, a busca pela justiça quando visualizam que outras tentativas não surtiram efeito. Porém, observamos que esse movimento acaba dando vazão à individualização das queixas escolares. A família é responsabilizada pelo fracasso escolar, a partir dos discursos científicos "competentes" e preconceituosos historicamente produzidos acerca da pobreza que sustentam conhecimentos sobre famílias, alunos e professores, desqualificando-os. A negligência e omissão dos pais, associada ao desinteresse e problemas emocionais de alunos mal comportados é a tradução das ideias que norteiam as orientações dos conselheiros aos alunos e familiares, bem como os encaminhamentos dos conseIheiros a outros setores.

A questão para a qual chamamos atenção é a de que em nenhum momento são questionadas as condições materiais de existência dos alunos e seus familiares, tampouco se questiona a organização e estrutura da educação. As queixas escolares aqui vistas não podem ser lidas como causadoras, mas sim, como produtos de uma educação que parece não estar cumprindo sua função.

Da mesma forma, um dos nossos propósitos consiste em apontar que os conflitos escolares se travestem de negligência familiar e assim são levados aos órgãos ligados à justiça. A queixa escolar, pois, quando explicada pela família omissa/negligente, tem respaldo para o repasse dos problemas encontrados no cotidiano escolar a uma outra esfera amparada no Direito da Criança e do Adolescente, qual seja, a justiça da infância e da juventude.

O fracasso escolar deve ser considerado como uma das contradições sociais; um produto, inclusive deliberado, da própria estrutura e organização social brasileira, prenhe de mediações que visam a manutenção da desigualdade social por parte da classe dominante. Desta forma, o foco dos esforços para a resolução da queixa por meio da legislação e de intervenções junto à família, apenas, não nos parece tarefa que irá solucionar os problemas da escolarização, haja vista a estrutura excludente da própria educação com seu modelo seriado e disciplinar, gerador de repetências e desinteresse.

Não é nosso objetivo afirmar que não deveriam ser buscados mecanismos para a garantia do direito à educação, tampouco que não existem situações que configuram maus tratos de familiares para com suas crianças/adolescentes. Pelo contrário, defendemos aqui que a educação é de fundamental importância para o desenvolvimento humano e, por isso, devem ser criados mecanismos para garantir sua universalidade. Da mesma forma, defendemos que crianças e adolescentes devem ser protegidas por seus familiares no sentido de permitir-lhes o pleno desenvolvimento nos termos da formação humana.

Todavia, entendemos que a evasão escolar, as faltas e o próprio conceito de negligência exigem uma leitura mais ampla, que considere as condições materiais de existência dos sujeitos, as contradições sociais e o movimento do Estado com relação às políticas sociais, de modo que apenas responsabilizar legalmente famílias tidas como culpadas pelo fenômeno da evasão e outros conflitos escolares é reduzir o fenômeno às suas mínimas abstrações, o que só poderia levar à proposição de ações ineficazes para os problemas da Educação no país, mantendo as relações excludentes da classe pobre trabalhadora.

Quando questionamos o papel da justiça diante da queixa escolar, entendemos sua própria contradição. É criada para resolver os conflitos da luta de classes, mas privilegiando a classe dominante, não podendo, assim, resolver o conflito mesmo que a criou, haja vista que não pode resolver a desigualdade inerente ao modo de produção capitalista. Destarte, a justiça da infância 
e juventude tende a mascarar e a lançar mão de estratégias paliativas para o fracasso escolar.

Há que se pensar, pois, na escola como expressão de uma sociedade desigual e também nos fatores que marcadamente situam os educandos e suas famílias em condições que não permitem sua permanência na escola. Essa leitura deve ser feita por todos os trabalhadores do SGD, motivo pelo qual um de nossos apontamentos para a transformação da realidade, a partir da pesquisa que aqui apresentamos, é o investimento na formação dos conselheiros tutelares, assim como dos demais profissionais do SGD. Sabemos que há capacitações, porém, defendemos aqui uma formação crítica que possibilite o "ir além das aparências" em direção à essência dos fenômenos que se apresentam, ou seja, uma formação que permita reconhecer as contradições da sociedade materializadas na queixa escolar.

Esperamos que esta pesquisa contribua para o repensar das práticas cotidianas dos diversos atores dos setores aqui mencionados para que possamos, de fato, garantir a crianças e adolescentes um direito humano básico e fundamental: o de humanizar-se. Consideramos que um trabalho científico tem seu valor, também, por consistir em nova janela que se abre para outras investigações. Entendendo que nosso trabalho não esgota as investigações necessárias na área, finalizamos com dois questionamentos que emergiram de nossa pesquisa e sugerem a continuidade de estudos acerca da relação entre Educação e Justiça da Infância e Juventude, quais sejam: qual o limite para que se acione o Ministério Público e Poder Judiciário? Até que ponto os mecanismos legais respondem às demandas reais dos sujeitos?

\section{REFERÊNCIAS}

Angelucci, C. B.; Kalmus, J.; Paparelli, R.; Patto, M. H. S. (2004). O estado da arte da pesquisa sobre o fracasso escolar (1991-2002): um estudo introdutório. Educação e Pesquisa, 30(1), 51-72.

Bazílio, L. C.; Kramer, S. (2011). Infância, educação e direitos humanos (4.ed.). São Paulo: Cortez

Boarini, M. L.; Borges, R. (2009). O Psicólogo na atenção básica à saúde. Psicologia: Ciência e Profissão, 29(3), 602-613.

Boarini, M. L. (2012). Higiene mental: ideias que atravessaram o século XX. Maringá: Eduem.

Brasil (1988). Constituição da República Federativa do Brasil: promulgada em 5 de outubro de 1988. São Paulo: Saraiva.

Collares, C. A. L.; Moysés, M. A. A. (2015). Preconceitos no cotidiano escolar: ensino e medicalização (2a. ed.). São Paulo: Ed. autor.

Duarte, N. (2012). Lukács e Saviani: a ontologia do ser social e a pedagogia histórico-crítica. In Saviani, D.; Duarte, N. (Eds.), Pedagogia histórico-crítica e luta de classes na educação escolar (pp.37-58). Campinas, SP: Autores Associados.
Facci, M. G. D; Meira, M. E. M.; Tuleski, S. C. (2012). A exclusão dos "incluídos": uma crítica da Psicologia da Educação à patologização e medicalização dos processos educativos (2a ed.). Maringá: Eduem.

Facci, M. G. D; Silva, S. M. C.; Ribeiro, M. J. L. (2012). Medicalização na escola e fracasso escolar: novamente a culpa é do aluno? In Facci, M. G. D; Meira, M. E. M.; Tuleski, S. C. (Eds.), A exclusão dos "incluídos": uma crítica da Psicologia da Educação à patologização e medicalização dos processos educativos (2a ed., pp. 157-186). Maringá: Eduem.

Figueira, F. F.; Boarini, M. (2014). Psicología e higiene mental en Brasil: la historia por contar. Universitas Psychologica, 13(5), 1801-1814.

Lei número 8.069 de 13 de julho de 1990 (1990, 13 de julho). Dispõe sobre o Estatuto da Criança e do Adolescente e dá outras providências. Brasília. Recuperado de http://www. planalto.gov.br/ccivil_03/leis/l8069.htm

Leonardo, N. S. T; Leal, Z. F. R. G.; Rossato, S. P. M. (Eds.) (2012). Pesquisas em queixa escolar: desvelando e desmistificando o cotidiano escolar. Maringá: Eduem.

Lessa, S. (2012). Da contestação à rendição. In Bertoldo, E; Moreira, L. A. L.; Jimenez, S. (Eds.), Trabalho, educação e formação humana frente à necessidade histórica de revolução. (pp.29-50). São Paulo: Instituto Lukács.

Martins, L. M. (2006). As aparências enganam: divergências entre o materialismo histórico dialético e as abordagens qualitativas de pesquisa. In Associação Nacional de PósGraduação e Pesquisa em Educação (ed.), 29ㅁ Reunião Anual da ANPED, CAXAMBU, MG. Recuperado de https://social.stoa.usp.br/articles/0016/4005/As_aparA_ ncias_enganam_-_divergencias_entre_o_mhd_e_as_ abordagens_qualitativas.pdf

Nagle, J. (1974). Educação e sociedade na Primeira República. São Paulo, EPU; Rio de Janeiro, Fundação Nacional de Material Escolar.

Patto, M. H. S. (1993). A produção do fracasso escolar: histórias de submissão e rebeldia. São Paulo: T.A. Queiroz, reimpressão.

Paula, F. S.; Tfouni, L. V. (2009). A persistência do fracasso escolar: desigualdade e ideologia. Revista Brasileira de Orientação Profissional, 10(2), 117-127

Reis, R. S.; Ribeiro, M. J. L. (2012). Queixa escolar: reflexões a partir da demanda de educandos em um projeto de extensão na UEM. In Leonardo, N. S. T.; Leal, Z. F. R. G.; Rossato, S. P. M. (Eds.), Pesquisas em queixa escolar: desvelando e desmistificando o cotidiano escolar. (pp.175203). Maringá: Eduem.

Rizzini, I.; Pilotti, F. (2009). A arte de governar crianças: a história das políticas sociais, da legislação e da assistência à infância no Brasil (2a ed.). São Paulo: Cortez, 2009.

Romanelli, O. O. (1986). História da educação no Brasil: 1930/1973. (8a ed.). Petrópolis: Vozes.

Saviani, D.; Duarte, N. (Eds.) (2012). Pedagogia históricocrítica e luta de classes na educação escolar. Campinas, SP: Autores Associados. 
Sêda, E. (1996). A proteção integral: um relato sobre o cumprimento do novo direito da criança e do adolescente na América Latina (4a ed.). Campinas: Edição Adês.

Silva, V. G.; Leonardo, N. S. T. (2012). Psicologia Histórico-Cultural e o desenvolvimento psíquico infantil: compreendendo o processo de escolarização e a queixa escolar. In. Leonardo, N. S. T.; Leal, Z. F. R. G.; Rossato, S. P. M. (Eds.), Pesquisas em queixa escolar: desvelando e desmistificando o cotidiano escolar. (pp.51-82). Maringá: Eduem, 2012.

Souza, M. P. R. (1997). A queixa escolar e o predomínio de uma visão de mundo. In: Machado, A. M.; Souza, M. P. R. (Eds.), Psicologia escolar: em busca de novos rumos. (pp.17-34). São Paulo: Casa do Psicólogo.

Souza, M. P. R; Teixeira, D. C. S.; Silva, M. C. Y. G. (2003). Conselho Tutelar: um novo instrumento social contra o fracasso escolar?. Psicologia em Estudo, 8(2), 71-82. https://dx.doi.org/10.1590/S1413-73722003000200008

Wanderbroock Junior, D. (2009). A educação sob medida: os testes psicológicos e o higienismo no Brasil (1914-45). Maringá: Eduem.

Recebido: 11 de janeiro de 2019 Aprovado: 10 de abril de 2019 